\title{
Mycobacterium holsaticum sp. nov.
}

${ }^{1}$ Forschungszentrum Borstel, National Reference Centre for Mycobacteria, D-23845 Borstel, Germany

${ }^{2}$ Max-Planck-Institute for Marine Microbiology, D-28359 Bremen, Germany

${ }^{3}$ Swiss National Centre for Mycobacteria, Department of Medical Microbiology, University of Zurich, $\mathrm{CH}-8028$ Zurich, Switzerland

\author{
Elvira Richter, ${ }^{1}$ Stefan Niemann, ${ }^{1}$ Frank O. Gloeckner, ${ }^{2}$ Gaby E. Pfyffer ${ }^{3}$ \\ and Sabine Rüsch-Gerdes ${ }^{1}$
}

Author for correspondence: Elvira Richter. Tel: +494537 188404. Fax: +494537 188311. e-mail: erichter@fz-borstel.de

\begin{abstract}
Strains of a novel species of the rapidly growing mycobacteria, Mycobacterium holsaticum sp. nov., were isolated from various clinical specimens. The isolates grew at $22-40{ }^{\circ} \mathrm{C}$, were positive for nitrate and tellurite reduction, had phosphatase, urease, nicotinamidase and pyrazinamidase activities, were resistant to isoniazid and rifampin and were susceptible to streptomycin and ethambutol. Analyses of the 16S rRNA gene and a fragment of the heat-shock protein gene $h s p 65$ revealed unique nucleotide sequences. A phylogenetic analysis based on the comparison of the 16S rDNA sequence with that of other mycobacterial species allocated the strain to the rapidly growing mycobacteria. A conspicuous characteristic of the novel species is the similarity of the species-specific sequence of the 16S rRNA gene to the sequence of the Mycobacterium tuberculosis complex, resulting in a cross-reaction with the AccuProbe for the $M$. tuberculosis complex when performed with a $5 \mathrm{~min}$ selection step. The type strain of the novel species is strain $1406^{\top}$ (= DSM $\mathbf{4 4 4 7 8}^{\mathrm{T}}$ = CCUG $46266^{\mathrm{T}}$ ). Another strain of $M$. holsaticum sp. nov., strain 5050 , which differed in the internal transcribed spacer sequence, was deposited as DSM 44479 (= CCUG 46267).
\end{abstract}

Keywords: Mycobacterium holsaticum sp. nov., 16S rRNA gene, internal transcribed spacer (ITS), heat-shock protein (hsp65), AccuProbe

\section{INTRODUCTION}

In recent years, the number of non-tuberculous mycobacteria (NTM) isolated from clinical specimens has increased greatly, partly due to opportunistic infections accompanying immunosuppression, but also as a result of improved culture and identification techniques (Hanna et al., 1999). On the other hand, an increasing number of mycobacterial species that exert very similar if not identical biochemical characteristics renders identification by classical methods more and more ineffective. The use of molecular methods such as DNA sequencing of the 16S rRNA gene overcomes these deficiencies, since most mycobacterial species are characterized by a unique $16 \mathrm{~S}$ rRNA gene sequence (Harmsen et al., 1999; Kirschner et al., 1993; Springer

Published online ahead of print on 19 April 2002 as DOI 10.1099/ ijs.0.01997-0.

Abbreviations: ITS, internal transcribed spacer; LJ, Löwenstein-Jensen $\mathrm{TCH}$, thiophene-2-carboxylic acid hydrazide; TSC, thiosemicarbazone.

The EMBL accession numbers for the $16 \mathrm{~S}$ rRNA, ITS1 and part of the $h s p 65$ gene sequence of strain DSM $44478^{\top}$ are AJ310467-AJ310469. The EMBL accession number for the ITS1 sequence of strain DSM 44479 is AJ310470. et al., 1996). However, one consequence of $16 \mathrm{~S}$ rDNA sequence determination in a reference laboratory is the finding of $16 \mathrm{~S}$ rDNA sequences not allocated to validly described species (Tortoli et al., 2001). Based on these 'new' sequences, the assumption can be drawn of a novel, so far undescribed mycobacterial species, which can be confirmed by additional biochemical characteristics and molecular features that differentiate these isolates from established species.

During recent years, several rapidly growing mycobacterial strains were collected at the German National Reference Centre for Mycobacteria. A group of isolates was characterized by an identical $16 \mathrm{~S}$ rDNA sequence, which was so far not released to nucleotide databases. In this study, we describe the phenotypic and genetic characteristics of these strains and propose a novel species, Mycobacterium holsaticum sp. nov.

\section{METHODS}

Strains. A total of nine mycobacterial strains characterized by an identical signature sequence of the $16 \mathrm{~S}$ rRNA gene was included in this study. They were isolated from clinical specimens [sputum $(n=6)$, urine (1), gastric fluid (1), 
unknown (1)]. All strains were isolated from different patients and originated from different regions in Germany. In the scope of this study, multiple isolates from one patient were not recorded. Strain $1406^{\mathrm{T}}\left(=\mathrm{DSM} 44478^{\mathrm{T}}=\mathrm{CCUG}\right.$ $\left.46266^{\mathrm{T}}\right)$ was isolated from sputum and strain 5050 (= DSM $44479=$ CCUG 46267) was isolated from urine.

Colony morphology, growth requirements and biochemical characterization. Colony morphology, pigmentation and the ability to grow at various temperatures $(22,31,37,40$ and $45^{\circ} \mathrm{C}$ ) on Löwenstein-Jensen (LJ) slants were determined and the following biochemical and physiological tests were performed on all nine strains: nitrate and tellurite reduction, hydrolysis of Tween 80, iron uptake, degradation of $p$ aminosalicylic acid, growth on MacConkey agar (without crystal violet) and on LJ slants in the presence of sodium chloride $(5 \%)$, thiophene-2-carboxylic acid hydrazide (TCH, $2 \mu \mathrm{g} \mathrm{ml}^{-1}$ ) and thiosemicarbazone (TSC, 0.5, 1 and $8 \mu \mathrm{g} \mathrm{ml}^{-1}$ ) (Deutsches Institut für Normung, 1996; Kent \& Kubica, 1985; Szabo \& Vandra, 1963; Wayne et al., 1974). In addition, activities of arylsulfatase, acetamidase, benzamidase, urease, nicotinamidase, phosphatase, pyrazinamidase, allantoinamidase, succinamidase and both heat-stable and semi-quantitative catalase were recorded (Bönicke, 1961 ; Kent \& Kubica, 1985; Kubica \& Pool, 1960; Marks \& Trollope, 1960). Growth on LJ slants in the presence of isoniazid $\left(0.25\right.$ and $\left.1.0 \mu \mathrm{g} \mathrm{ml}^{-1}\right)$, streptomycin $(4.0$ and $\left.8 \cdot 0 \mu \mathrm{g} \mathrm{ml}^{-1}\right)$, ethambutol $\left(1 \cdot 0\right.$ and $\left.2 \cdot 0 \mu \mathrm{g} \mathrm{ml}^{-1}\right)$, rifampin $(16$ and $32 \mu \mathrm{g} \mathrm{ml}^{-1}$ ), protionamide (16 and $32 \mu \mathrm{g} \mathrm{ml}^{-1}$ ) and ofloxacin $\left(0 \cdot 5,1,2\right.$ and $\left.4 \mu \mathrm{g} \mathrm{ml}^{-1}\right)$ was determined (Deutsches Institut für Normung, 1996).

Lipid analyses. Mycolic acids were analysed by TLC (Minnikin, 1993; Minnikin et al., 1984) and cellular fatty acids by GLC (Luquin et al., 1991) from two strains. Samples were processed as described elsewhere (Brown et al., 1999).

AccuProbe assays. AccuProbe assays (Gen-Probe) for the Mycobacterium tuberculosis complex were performed according to the manufacturer's instructions, except that the selection step was $5 \mathrm{~min}$ instead of $10 \mathrm{~min}$. In addition, AccuProbe assays for the $M$. tuberculosis complex were performed with a 10 min selection step, as recommended, from five strains.

Measurement of $\mathbf{G}+\mathbf{C}$ content of DNA. Mycobacteria were cultured on LJ slants. DNA extraction, purification and degradation and $\mathrm{G}+\mathrm{C}$ content determination by HPLC were performed as described by Mesbah et al. (1989), except that a Waters 486 tuneable absorbance detector plus a Waters 746 data module (Millipore/Waters) were used.

Preparation of DNA. Strains were grown on LJ slants or in liquid medium (BACTEC 460TB 12B medium). From solid media, one loopful of bacteria was suspended in distilled water, sonicated for $15 \mathrm{~min}$ and boiled in a waterbath for $15 \mathrm{~min}$. The suspension was used directly for PCR. If cells grew in liquid medium, $2 \mathrm{ml}$ culture medium were centrifuged (12000 $\mathrm{g}, 10 \mathrm{~min}$, room temperature) and the pellet was resuspended in distilled water, centrifuged again and finally resuspended in $100 \mu$ distilled water prior to sonication and heating.

Nucleic acid analyses. For identification of mycobacteria, amplification of the $5^{\prime}$ part of the $16 \mathrm{~S}$ rRNA gene using primers A (Edwards et al., 1989) and 264 (Böddinghaus et al., 1990) and additional sequencing of the hypervariable regions A and B (Kirschner et al., 1993) was performed from all nine isolates. Based on identical sequences resulting from this determination, four strains were chosen for complete
16S rRNA analysis. For this, amplification of an approximately $2100 \mathrm{bp}$ DNA fragment comprising the entire 16S rRNA gene and the internal transcribed spacer (ITS) was performed using primers targeting the promoter sequence of the rRNA operon (primer P2; 5'-GTGTTGTTTGAGAACTCAATAGT-3') and the 5'-region of the 23S rRNA gene (primer ITS2; Richter et al., 1999). The complete PCR product was sequenced on an automated DNA sequencer (ABI 377; Applied Biosystems) by cycle sequencing using the Big Dye RR Terminator cycle sequencing kit (Applied Biosystems) according to the manufacturer's instructions, using a set of internal primers [forward primers 14 (5'-CGAGTGGCGAACGGGTGAGTAACA$\left.3^{\prime}\right), 10$ (5'-GAGCTCGTAGGTGGTTTGTC-3') and 19 (5'-TTACCTGGGTTTGACATG-3'); reverse primers 4 (5'-GCCGTATCTCAGTCCCAGTG-3'), 247 and 264 (Böddinghaus et al., 1990)] and the PCR primers. The resulting sequences were aligned and compared to the sequences of the International Nucleotide Sequence Database Collaboration (Altschul et al., 1997).

The ITS sequence was analysed from the remaining five isolates for which the $16 \mathrm{~S}$ rDNA sequence was not completely determined. For amplification, primers were used that targeted the $3^{\prime}$ end of the $16 \mathrm{~S}$ rRNA gene and the $5^{\prime}$ end of the 23S rRNA gene, as described previously (Richter et al., 1999). Both PCR primers were also used as sequencing primers. The resulting sequences were aligned and compared to the sequences of the International Nucleotide Sequence Database Collaboration.

Amplification of part of the heat-shock protein gene hsp65 of all nine strains was performed according to Telenti et al. (1993). The resulting PCR product was sequenced using the PCR primers and analysed for restriction sites as well as used for RFLP analysis following digestion with the restriction enzymes BstEII and HaeIII (Telenti et al., 1993).

Sequence and phylogenetic analyses. The resulting $16 \mathrm{~S}$ rDNA sequence was added to the rDNA sequence database of the Technical University Munich (release December 1998) using the program package ARB (Strunk et al., 2001). The tool ARB_ALIGN was used for automatic sequence alignment. The resulting alignments were checked and corrected manually, considering the secondary structure of the rRNA molecule. The ARB database was supplemented by importing several 16S rDNA sequences from mycobacteria. Tree topologies were evaluated by performing maximum-parsimony, neighbour-joining and maximum-likelihood analysis. Sequences were used for treeing only if they were at least $90 \%$ complete. Alignment positions at which fewer than $50 \%$ of the sequences of the entire dataset shared the same residue were excluded from the calculations.

\section{RESULTS AND DISCUSSION}

\section{Microscopy and phenotypic characteristics}

Cells of the novel isolates were acid-alcohol-fast and appeared as short or coccoid rods. Colony morphology was dependent on the incubation temperature: at $22^{\circ} \mathrm{C}$, the colonies were very dysgonic and transparent, whereas at higher temperatures, the strains grew in smooth, moist, shiny, off-white to yellowpigmented colonies within 7 days at temperatures up to $40{ }^{\circ} \mathrm{C}$. All of the novel strains were homogeneous in their biochemical properties: they were positive for nitrate and tellurite reduction, tolerated $5 \% \mathrm{NaCl}$, $2 \mu \mathrm{g} \mathrm{TCH} \mathrm{ml} l^{-1}$ and $8 \mu \mathrm{g} \mathrm{TSC} \mathrm{ml} l^{-1}$ and exhibited 
Table 1. Differential characteristics of $M$. holsaticum sp. nov. and selected rapidly growing mycobacteria

Common characters for all taxa: resistance to isoniacid and rifampin, positive 8-day tellurite reduction, growth at 31 and $37{ }^{\circ} \mathrm{C}$, presence of urease, nicotinamidase and pyrazinamidase and presence of $\alpha$-mycolic acids. Data for reference taxa were taken from Wayne \& Kubica (1986). +, Positive; +/-, variable; -, negative; ND, not determined; PAS, $p$-aminosalicylic acid.

\begin{tabular}{|c|c|c|c|c|}
\hline Characteristic & M. holsaticum & M. fortuitum & M. chelonae & M. smegmatis \\
\hline Pigmentation & $+1-$ & - & - & + \\
\hline \multicolumn{5}{|l|}{ Growth at: } \\
\hline $22{ }^{\circ} \mathrm{C}$ & + & + & + & ND \\
\hline $40^{\circ} \mathrm{C}$ & + & -* & - & + \\
\hline $45^{\circ} \mathrm{C}$ & - & - & - & + \\
\hline Growth on MacConkey & - & + & + & - \\
\hline Nitrate reduction & + & + & - & + \\
\hline Tellurite reduction 3 days & - & + & + & + \\
\hline Tween hydrolysis & $+1-$ & - & - & - \\
\hline Iron uptake & - & + & - & + \\
\hline PAS degradation & - & - & + & - \\
\hline $\mathrm{NaCl}$ tolerance & + & + & - & + \\
\hline TSC tolerance & + & ND & $\mathrm{ND}$ & ND \\
\hline Arylsulfatase & - & + & + & - \\
\hline Phosphatase & + & + & + & - \\
\hline \multicolumn{5}{|l|}{ Amidases: } \\
\hline Acetamidase & - & + & + & + \\
\hline Benzamidase & - & - & - & + \\
\hline Allantoinamidase & - & + & - & + \\
\hline Succinamidase & - & - & - & + \\
\hline Catalase $\left(68^{\circ} \mathrm{C}\right)$ & - & + & - & - \\
\hline Mycolic acids & methoxy, keto & $\alpha^{\prime}$, epoxy, methoxy & $\alpha^{\prime}$ & $\alpha^{\prime}$, epoxy \\
\hline \multicolumn{5}{|l|}{ Susceptibility to $:$} \\
\hline Streptomycin & $\mathrm{S}$ & $\mathrm{R}$ & $\mathrm{R}$ & $\mathrm{S}$ \\
\hline Ethambutol & $\mathrm{S}$ & $\mathrm{R}$ & $\mathrm{R}$ & $\mathrm{S}$ \\
\hline Protionamide & $\mathrm{S}$ & $\mathrm{R}$ & $\mathrm{R}$ & $\mathrm{R}$ \\
\hline Ofloxacin & $\mathrm{S}$ & $\mathrm{S}$ & $\mathrm{R}$ & $\mathrm{S}$ \\
\hline
\end{tabular}

* Poor growth is sometimes observed.

$\dagger$ R, Resistant; S, susceptible.

phosphatase, urease, nicotinamidase and pyrazinamidase activities. Some isolates were weakly positive for Tween 80 hydrolysis. The strains did not take up iron or degrade $p$-aminosalicylic acid. Arylsulfatase, acetamidase, benzamidase, allantoinamidase, succinamidase and stable catalase activities were leaking. They did not grow on MacConkey agar. The strains were resistant to isoniazid and rifampin, but susceptible to streptomycin, ethambutol, protionamide and ofloxacin. Characteristics that differentiate the novel isolates from other rapidly growing mycobacteria often isolated are summarized in Table 1.

\section{Lipid analysis}

Major mycolic acids were $\alpha$-, methoxy- and ketomycolic acids. Cellular fatty acids ranged from $\mathrm{C} 10: 0$ to $\mathrm{C} 20$ : 0 , the major components being $\mathrm{C} 16: 0(24 \cdot 7 \%)$ and $\mathrm{C} 18: 1 \omega 9 c(26.4 \%)$. Minor components were $\mathrm{C} 10: 0(<1 \%), \mathrm{C} 11: 0(<1 \%), \mathrm{C} 12: 0(1 \cdot 8 \%), \mathrm{C} 14: 0$ $(4 \cdot 1 \%), \mathrm{C} 15: 0(<1 \%), \mathrm{C} 16: 1 \omega 9 c(4 \cdot 2 \%), \mathrm{C} 16: 1 \omega 7 c$
$(2 \cdot 2 \%), \mathrm{C} 16: 1 \omega 6 c(5 \cdot 1 \%), \mathrm{C} 17: 1 \omega 7 c(7 \cdot 4 \%), \mathrm{C} 17: 0$ $(<1 \%), \mathrm{C} 18: 2 \omega 6,9 c \quad(<1 \%), \mathrm{C} 18: 1 \omega 7 c \quad(<1 \%)$, C18:0 (3.3\%), tuberculostearic acid (10Me-18:0; $5 \cdot 8 \%)$ C20:0 ALC (12.7\%) and C20:0 (<1\%).

\section{$\mathbf{G}+\mathbf{C}$ content of DNA}

The $\mathrm{G}+\mathrm{C}$ content of the DNA was $68.4 \mathrm{~mol} \%$.

\section{S rRNA sequence analysis}

Analysis of the complete 16S rRNA gene of the novel isolates, representing $M$. holsaticum sp. nov., revealed a unique sequence. In the International Nucleotide Sequence database, there was no entry with an identical sequence. The 16S rRNA gene of $M$. holsaticum sp. nov. is characterized by a short helix in the hypervariable region 18 , a characteristic of rapidly growing mycobacteria. With regard to the mycobacterial species-specific region V2 of helix 10, the sequence of $M$. holsaticum sp. nov. is remarkably similar 


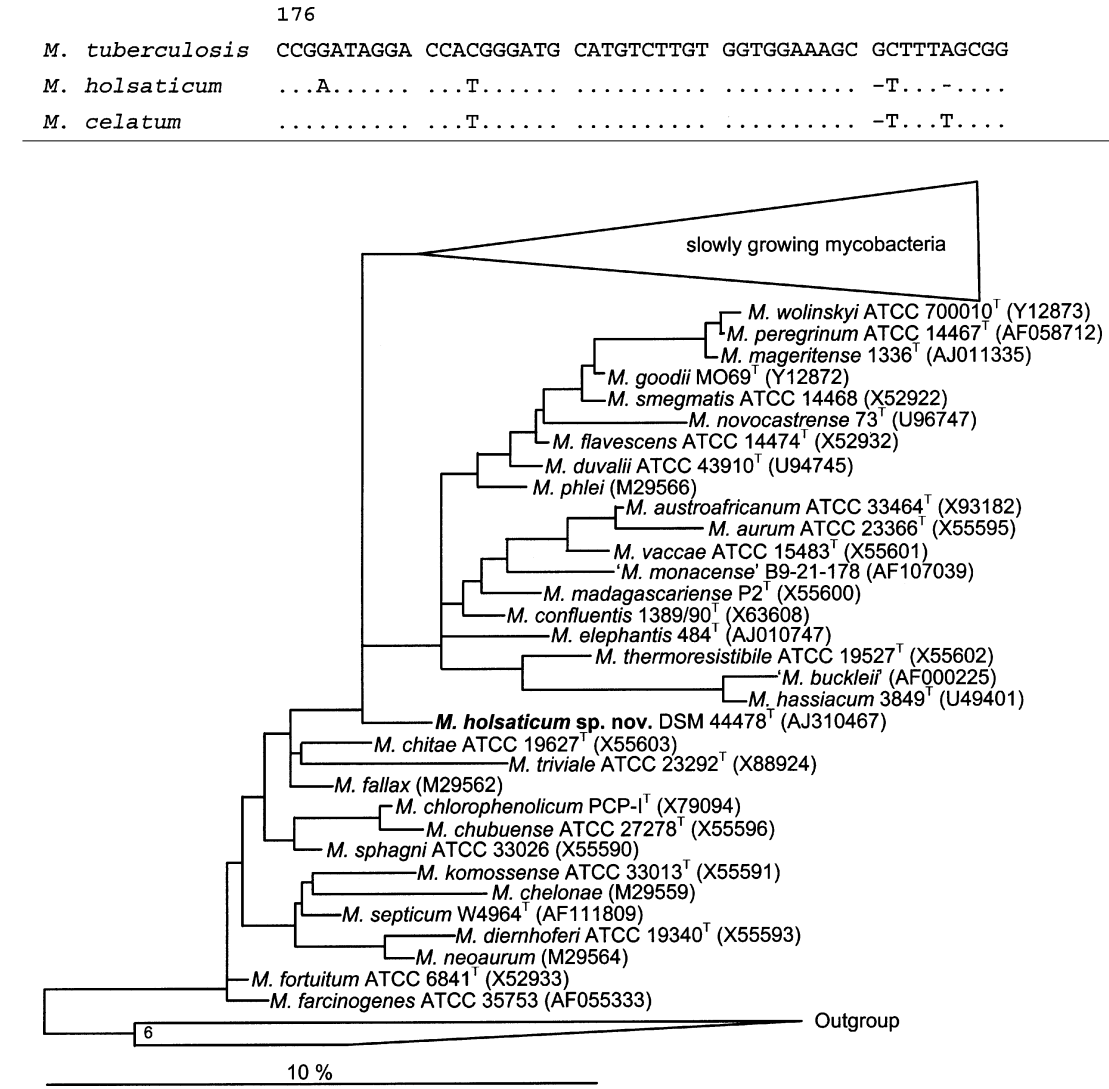

Fig. 1. Species-specific region V2 of helix 10 of the 16S rRNA genes of $M$. tuberculosis, $M$. holsaticum sp. nov. and $M$. celatum. Numbering corresponds to the Escherichia coli $16 \mathrm{~S}$ rRNA gene. For M. holsaticum and $M$. celatum, only bases that differ from those of $M$. tuberculosis are given; dots indicate identity with $M$. tuberculosis, deletions are marked by dashes. to the sequences of M.tuberculosis and Mycobacterium celatum, differing in only a few bases (Fig. 1).

\section{Phylogenetic analysis}

Phylogenetic sequence analysis allocated the species into the group of rapidly growing mycobacteria. Trees were reconstructed only on nearly full-length sequences ( $>1300$ bases) using maximum-parsimony, neighbour-joining and maximum-likelihood analyses in combination with different filters. The tree shown in Fig. 2 is based on maximum-likelihood analysis and was corrected by taking into consideration the different results of various tree-reconstruction algorithms. Bifurcations indicate branching that appeared stable by all three methods and were well separated from neighbouring branches in all cases. Multifurcations indicate tree topologies that could not be resolved significantly on the basis of the dataset available.

\section{Sequence analysis of the ITS}

Interspecific polymorphism of the 16S-23S rRNA ITS can be used for differentiation of mycobacteria (Kraus et al., 2001; Park et al., 2000; Roth et al., 1998, 2000). Analysis of the ITS of $M$. holsaticum sp. nov. revealed
Fig. 2. Maximum-likelihood tree based on 1427 positions of nearly full-length $16 \mathrm{~S}$ rRNA sequences derived from 200 Mycobacterium species. The dendrogram of slowly growing mycobacteria was condensed. Selected sequences from Grampositive organisms with high $\mathrm{G}+\mathrm{C}$ content were taken to root the tree. Trees constructed with other tree reconstruction algorithms (neighbour-joining and parsimony) generally resulted in the same overall tree topology. Bar, 10\% estimated sequence divergence. two sequences that differed in an insertion of $10 \mathrm{bp}$, in spite of identical 16S rDNA sequences. Strain-tostrain variation in this region is known from several mycobacteria (Roth et al., 1998, 2000; Richter et al., 1999), particularly from environmental species (Frothingham, 1999). Database analyses using both sequences revealed no identical entries.

\section{hsp65 sequence and RFLP analysis}

Analysis of part of the mycobacterial hsp65 gene is a widely applied method for identification of mycobacterial species (Devallois et al., 1997; Ringuet et al., 1999; Telenti et al., 1993; Steingrube et al., 1995). Sequencing of the $h s p 65$ PCR product from $M$. holsaticum sp. nov. resulted in a unique nucleotide sequence compared with the sequences stored in the International Nucleotide Sequence Database (Altschul et al., 1997). The M. holsaticum hsp65 fragment contains no restriction site for BstEII, but six restriction sites for HaeIII, resulting in seven restriction fragments with the following fragment sizes: 139, 96, $58,51,36,36$ and 23 bp. By gel electrophoresis of the RFLP assay using HaeIII, a pattern of four fragments of approximately 140, 100, 60 and $30 \mathrm{bp}$ can be visualized. Absence of a BstEII restriction site discri- 
minates the strains clearly from most rapidly growing mycobacteria, particularly from the Mycobacterium fortuitum complex, the hsp65 PCR fragment of which contains at least one restriction site for BstEII (Devallois et al., 1997).

\section{AccuProbe results}

In clinical mycobacteriology laboratories, commercially available RNA probes (AccuProbes), targeting rRNA and known to be highly sensitive and specific (Lebrun et al., 1992), are widely used to identify the $M$. tuberculosis complex. However, M. celatum, an NTM species, has been reported to cross-react with the $M$. tuberculosis complex probe, due to similarities in the very part of the $16 \mathrm{~S}$ rRNA gene (Fig. 1) that is targeted by the RNA probe, thus leading to a false-positive result (Bux-Gwehr et al., 1998; Somoskövi et al., 2000). As a consequence, an improved protocol with a prolonged selection step is recommended to circumvent this cross-reactivity. However, false-positive results are still reported, probably because of incorrect performance of the test.

Due to the high similarity of the species-specific $16 \mathrm{~S}$ rDNA sequences of $M$. holsaticum sp. nov. and the $M$. tuberculosis complex (Fig. 1), cross-reactivity can also be observed when performing an AccuProbe assay with the $M$. tuberculosis complex probe on $M$. holsaticum strains with a 5 min selection step (RLU values ranging from 40090 to 168662 ). In contrast, with a 10 min selection step, the results for all strains investigated were negative (1377 to 1890 RLU). Thus, in the case of a positive M. tuberculosis complex AccuProbe result, combined with rapid growth in culture or atypical morphology, $M$. holsaticum has to be taken into account.

\section{Combined molecular and phenotypic features}

Analysis of the entire 16S rRNA gene, revealing a unique sequence, and determination of unique sequences of the ITS and the hsp65 PCR fragment provide genetic evidence for a novel species belonging to the rapidly growing mycobacteria, as demonstrated by phylogenetic analyses. Phenotypic features, like susceptibility to streptomycin and ethambutol, the inability to take up iron and the mycolic acid pattern, confirm this assessment of a novel species.

\section{Characteristics that differentiate $M$. holsaticum sp. nov. from other rapidly growing mycobacteria}

$M$. holsaticum sp. nov. can be differentiated easily from the $M$. fortuitum complex by its morphology, absence of arylsulfatase and allantoinase, absence of growth on MacConkey agar and susceptibility to streptomycin and ethambutol. It differs from many rapidly growing mycobacteria in the inability to take up iron and the absence of acetamidase. Furthermore, $M$. holsaticum is characterized by a unique $16 \mathrm{~S}$ rDNA sequence, placing the species in the rapidly growing mycobacteria, and a unique hsp65 sequence with a unique RFLP pattern.

\section{Description of Mycobacterium holsaticum sp. nov.}

Mycobacterium holsaticum (hol.sa'ti.cum. L. adj. holsaticum referring to the German region of Holstein, the location of the institute in which the strains were first analysed).

Cells are acid-alcohol-fast, short or coccoid rods. Colonies are dysgonic and transparent at $22{ }^{\circ} \mathrm{C}$, but smooth, moist, shiny and off-white- to yellow-pigmented at higher temperatures. Isolates grow within 7 days at temperatures up to $40{ }^{\circ} \mathrm{C}$. Strains are positive for nitrate and tellurite reduction, tolerate $5 \% \mathrm{NaCl}$, $2 \mu \mathrm{g} \mathrm{TCH} \mathrm{ml} l^{-1}$ and $8 \mu \mathrm{g} \mathrm{TSC} \mathrm{ml}{ }^{-1}$, have phosphatase, urease, nicotinamidase and pyrazinamidase activities and are weakly positive for Tween 80 hydrolysis. They do not take up iron and can not degrade $p$-aminosalicylic acid. There is no arylsulfatase, acetamidase, benzamidase, allantoinamidase, succinamidase or heat-stable catalase activity. The strains are resistant to isoniazid and rifampin, but susceptible to streptomycin, ethambutol, protionamide and ofloxacin. Cell walls contain predominantly $\alpha$-, methoxy- and ketomycolates. Major cellular fatty acids are C16:0, C18: $1 \omega 9 c$ and tuberculostearic acid. The $\mathrm{G}+\mathrm{C}$ content of the DNA is $68.4 \mathrm{~mol} \%$. Analysis of the entire 16S rRNA gene provides genetic evidence for a novel species. Phylogenetic analysis based on the 16S rDNA sequence allocates this species to the rapidly growing mycobacteria. Sequences of ITS and the hsp65 PCR fragment are also unique.

The type strain, $1406^{\mathrm{T}}\left(=\mathrm{DSM} 44478^{\mathrm{T}}=\mathrm{CCUG}\right.$ $\left.46266^{\mathrm{T}}\right)$, has a long ITS sequence. Strain 5050 $(=\mathrm{DSM} 44479=\mathrm{CCUG} 46267)$ has a short ITS sequence.

\section{ACKNOWLEDGEMENTS}

We thank B. Schlüter, I. Radzio, F. Schaefer and S. Groth, Borstel, Germany, and A. Strässle and R. Wirth, Zurich, Switzerland, for excellent technical assistance. Financial support from the Swiss Federal Office of Public Health is gratefully acknowledged.

\section{REFERENCES}

Altschul, S. F., Madden, T. L., Schäffer, A. A., Zhang, J., Zhang, Z., Miller, W. \& Lipman, D. J. (1997). Gapped BLAST and PSI-BLAST : a new generation of protein database search programs. Nucleic Acids Res 25, 3389-3402.

Böddinghaus, B., Rogall, T., Flohr, T., Blöcker, H. \& Böttger, E. C. (1990). Detection and identification of mycobacteria by amplification of rRNA. J Clin Microbiol 28, 1751-1759.

Bönicke, R. (1961). Die Bedeutung der Acylamidasen für die Identifizierung und Differenzierung der verschiedenen Arten der Gattung Mycobacterium. Jahresber Borstel 5, 7-87.

Brown, B. A., Springer, B., Steingrube, V. A. \& 10 other authors (1999). Mycobacterium wolinskyi sp. nov. and Mycobacterium goodii 
sp. nov., two new rapidly growing species related to Mycobacterium smegmatis and associated with human wound infections: a cooperative study from the International Working Group on Mycobacterial Taxonomy. Int J Syst Bacteriol 49, 1493-1511.

Bux-Gewehr, I., Hagen, H. P., Rüsch-Gerdes, S. \& Feurle, G. E. (1998). Fatal pulmonary infection with Mycobacterium celatum in an apparently immunocompetent patient. J Clin Microbiol 36, 587-588.

Deutsches Institut für Normung (1996). DIN 58943, parts 8 and 9 . Berlin: Beuth.

Devallois, A., Goh, K. S. \& Rastogi, N. (1997). Rapid identification of mycobacteria to species level by PCR-restriction fragment length polymorphism analysis of the hsp65 gene and proposition of an algorithm to differentiate 34 mycobacterial species. J Clin Microbiol 35, 2969-2973.

Edwards, U., Rogall, T., Blocker, H., Emde, M. \& Bottger, E. C. (1989). Isolation and direct complete nucleotide determination of entire genes. Characterisation of a gene coding for $16 \mathrm{~S}$ ribosomal RNA. Nucleic Acids Res 17, 7843-7853.

Frothingham, R. (1999). Evolutionary bottlenecks in the agents of tuberculosis, leprosy, and paratuberculosis. Med Hypotheses 52, 95-99.

Hanna, B. A., Ebrahimzadeh, A., Elliott, L. B. \& 9 other authors (1999). Multicenter evaluation of the BACTEC MGIT 960 system for recovery of mycobacteria. J Clin Microbiol 37, 748-752.

Harmsen, D., Rothgänger, J., Singer, C., Albert, J. \& Frosch, M. (1999). Intuitive hypertext-based molecular identification of microorganisms. Lancet 353, 291. http://www.ridom.de

Kent, P. T. \& Kubica, G. P. (1985). Public Health Laboratory. A Guide for the Level III Laboratory. Atlanta, GA: US Department of Health and Human Services, Centers for Disease Control.

Kirschner, P., Springer, B., Vogel, U., Meier, A., Wrede, A., Kiekenbeck, M., Bange, F. C. \& Bottger, E. C. (1993). Genotypic identification of mycobacteria by nucleic acid sequence determination: report of a 2-year experience in a clinical laboratory. J Clin Microbiol 31, 2882-2889.

Kraus, G., Cleary, T., Miller, N., Seivright, R., Young, A. K., Spruill, G. \& Hnatyszyn, H. J. (2001). Rapid and specific detection of the Mycobacterium tuberculosis complex using fluorogenic probes and realtime PCR. Mol Cell Probes 15, 375-383.

Kubica, G. P. \& Pool, G. L. (1960). Studies on the catalase activity of acid-fast bacilli. Am Rev Resp Dis 81, 387-391.

Lebrun, L., Espinasse, F., Poveda, J. P. \& Vincent-Levy-Frébault, V. (1992). Evaluation of nonradioactive DNA probes for identification of mycobacteria. J Clin Microbiol 30, 2476-2478.

Luquin, M., Ausina, V., Lopez Calahorra, F., Belda, F., Garcia Barcelo, M., Celma, C. \& Prats, G. (1991). Evaluation of practical chromatographic procedures for identification of clinical isolates of mycobacteria. J Clin Microbiol 29, 120-130.

Marks, J. \& Trollope, D. R. (1960). A study of the 'anonymous' mycobacteria. 1. Introduction; colonial characteristics and morphology; growth rates; biochemical tests. Tubercle 41, 51-62.

Mesbah, M., Premachandran, U. \& Whitman, W. B. (1989). Precise measurement of the $\mathrm{G}+\mathrm{C}$ content of deoxyribonucleic acid by highperformance liquid chromatography. Int J Syst Bacteriol 39, 159-167. Minnikin, D. E. (1993). Mycolic acids. In CRC Handbook of Chromatography - Analysis of Lipids, pp. 189-256. Edited by K. D. Mukherjee \& N. Weber. Boca Raton, FL: CRC Press.

Minnikin, D. E., Minnikin, S. M., Parlett, J. H. \& Goodfellow, M. (1984). Extraction of mycobacterial mycolic acids and other long-chain compounds by an alkaline methanolysis procedure. $J$ Microbiol Methods 2, 243-249.

Park, H., Jang, H., Kim, C., Chung, B., Chang, C. L., Park, S. K. \& Song, S. (2000). Detection and identification of mycobacteria by amplification of the internal transcribed spacer regions with genus- and species-specific PCR primers. J Clin Microbiol 38, 4080-4085.

Richter, E., Niemann, S., Rüsch-Gerdes, S. \& Hoffner, S. (1999). Identification of Mycobacterium kansasii by using a DNA probe (AccuProbe) and molecular techniques. J Clin Microbiol 37, 964-970.

Ringuet, H., Akoua-Koffi, C., Honore, S., Varnerot, A., Vincent, V., Berche, P., Gaillard, J. L. \& Pierre-Audigier, C. (1999). hsp65 sequencing for identification of rapidly growing mycobacteria. J Clin Microbiol 37, 852-857.

Roth, A., Fischer, M., Hamid, M. E., Michalke, S., Ludwig, W. \& Mauch, H. (1998). Differentiation of phylogenetically related slowly growing mycobacteria based on $16 \mathrm{~S}-23 \mathrm{~S}$ rRNA gene internal transcribed spacer sequences. J Clin Microbiol 36, 139-147.

Roth, A., Reischl, U., Streubel, A., Naumann, L., Kroppenstedt, R. M., Habicht, M., Fischer, M. \& Mauch, H. (2000). Novel diagnostic algorithm for identification of mycobacteria using genus-specific amplification of the $16 \mathrm{~S}-23 \mathrm{~S}$ rRNA gene spacer and restriction endonucleases. J Clin Microbiol 38, 1094-1104.

Somoskövi, A., Hotaling, J. E., Fitzgerald, M., Jonas, V., Stasik, D., Parsons, L. M. \& Salfinger, M. (2000). False-positive results for Mycobacterium celatum with the AccuProbe Mycobacterium tuberculosis complex assay. J Clin Microbiol 38, 2743-2745.

Springer, B., Stockman, L., Teschner, K., Roberts, G. D. \& Bottger, E. C. (1996). Two-laboratory collaborative study on identification of mycobacteria: molecular versus phenotypic methods. J Clin Microbiol 34, 296-303.

Steingrube, V. A., Gibson, J. L., Brown, B. A., Zhang, Y., Wilson, R. W., Rajagopalan, M. \& Wallace, R. J., Jr (1995). PCR amplification and restriction endonuclease analysis of a 65-kilodalton heat shock protein gene sequence for taxonomic separation of rapidly growing mycobacteria. J Clin Microbiol 33, 149-153.

Strunk, O., Gross, O., Reichel, B. \& 11 other authors (2001). ARB : a software environment for sequence data. Department of Microbiology. Technische Universität München, Germany. http://www.mikro. biologie.tu.muenchen.de

Szabo, I. \& Vandra, E. (1963). Mycobacterium minetti (Penso et al. 1952) bacteriological and epidemiological observations. Acta Microbiol Acad Sci Hung 10, 215-223.

Telenti, A., Marchesi, F., Balz, M., Bally, F., Böttger, E. C. \& Bodmer, T. (1993). Rapid identification of mycobacteria to the species level by polymerase chain reaction and restriction enzyme analysis. J Clin Microbiol 31, 175-178.

Tortoli, E., Bartoloni, A., Bottger, E. C. \& 8 other authors (2001). Burden of unidentifiable mycobacteria in a reference laboratory. J Clin Microbiol 39, 4058-4065.

Wayne, L. G. \& Kubica, G. P. (1986). Genus Mycobacterium Lehmann and Neumann 1896, 363 ${ }^{\mathrm{AL}}$, In Bergey's Manual of Systematic Bacteriology, vol. 2, pp. 1436-1457. Edited by P. H. A. Sneath, N. S. Mair, M. E. Sharpe \& J. G. Holt. Baltimore: Williams \& Wilkins.

Wayne, L. G., Engbaek, H. C., Engel, H. W. B. \& 17 other authors (1974). Highly reproducible techniques for use in systematic bacteriology in the genus Mycobacterium: tests for pigment, urease, resistance to sodium chloride, hydrolysis of Tween 80 , and $\beta$-galactosidase. Int J Syst Bacteriol 24, 412-419. 